\title{
Human Cell or Tissue Harvest
}

National Cancer Institute

\section{Source}

National Cancer Institute. Human Cell or Tissue Harvest. NCI Thesaurus. Code C113015.

The process by which human donor cells or tissues are obtained for use in human implantation, transplantation, infusion, or transfer. 